\title{
Construction and Innovation of Internet-based Ideological and Political Education Method
}

\author{
Jingyun Zheng \\ Ideological and Political Department, Guangdong AIB Polytechnic College, Guangzhou, 510507, \\ China
}

Keywords: Internet, Ideology and politics, Construction of educational method, Innovation

\begin{abstract}
As information technology develops rapidly, the status of internet in current times is increasingly indispensable. To deeply implement internet-based ideological and political education, actively construct and innovate for ideological and political education system has very important practical significance for improving the level of ideological and political education.
\end{abstract}

\section{Foreword}

Only after the method of internet-based ideological and political education are established and perfected, the objective of internet-based ideological and political education can be achieved smoothly; coordination, guidance and incentive functions of ideological and political education can be exerted. Meanwhile, perfection of the method of internet-based ideological and political education has the direct bearing on improvement of the effectives of internet-based ideological and political education. This method is ideological and political education under the environment of network technique. In the process of ideological and political education, internet served as a tool and means. This method pays attention to giving play to the function of internet in the education process. This paper discusses construction and innovation of internet-based ideological and political education.

\section{Value of internet-based ideological and political education}

From the viewpoint of philosophy, the method is the sum of means, procedures and ways adopted in order to reach certain purposes in the process where people cognize and transform the world. The method is a type of relative category closely connected with human activities. It is not an entity category or an entity factor. The existence base and value of a method are based on close connection with human practical activities. The method of internet-based ideological and political education and virtual practical activities in internet are always closely related. Educational method gradually forms in virtual practice. Besides, related rules of internet-based ideological and political education are developed. This is the precondition of implementation of internet-based ideological and political education and also core means to achieve educational objective. The method of internet-based ideological and political education to some extent has an irreplaceable role in realizing educational objectives, completing educational tasks and ensuring effectiveness of internet-based ideological and political education. Its values are reflected in the following three aspects:

\section{As a means to achieve the purpose of internet-based ideological and political education}

The purpose of internet-based ideological and political education is to carry out ideological and political education in a virtual society and make thoughts and behaviors of the audiences relatively stable in the virtual society and comply with mainstream thoughts of real society. To achieve this purpose, it is necessary to selectively choose effective educational methods in accordance with features of the virtual society, thought and behavior characteristics of the audiences in the virtual society. The method is an important means to achieve the purpose. If the objective is set and there is no method to achieve the objective, internet-based ideological and political education is just of empty talk. The purpose of internet-based ideological and political education cannot be achieved. So, the method has important significance for realization of the purpose. Whether the method of internet-based ideological and political education can be correctly applied concerns whether the 
purpose of internet-based ideological and political education can be achieved. Only when the correct method is applied in the process of internet-based ideological and political education can educational effect be exerted. Besides, educational tasks can be completed.

\section{As a hub to connect subjects and objects of education}

Internet-based ideological and political education can be effectively conducted only when subjects of education carry out education activities smoothly and objects of education learn with quality and quantity guaranteed in the process of internet-based ideological and political education. In essence, activities of internet-based ideological and political education are based on coordinated, equal, democratic and negotiating relations between subjects and objects of education. It is an interaction process. To accomplish set educational objectives and reach good educational effects, it is necessary to select educational methods which can make subjects and objects of education establish harmonious, equal and interactive relations in the process of internet-based ideological and political education so as to improve effectiveness, scientificity and rationality of internet-based ideological and political education and help educational activities proceed smoothly. Thus, firstly, educational methods selected in the activities of internet-based ideological and political education should accord with the law of ideological and political education. Secondly, human thought and behavior characteristics in the virtual society should govern. In the activities of ideological and political education, subjects of education should make sure the contents of internet-based ideological and political education can be spread, educational tasks can be smoothly completed and educational effects can improve through applying effective educational methods. The internet audiences (i.e. objects of education) need to apply appropriate manners and methods to democratically negotiate and harmoniously communicate with subjects of education in an active manner in the virtual society, promote formation of good interaction relationship, give play to democratic and absorb positive energy of internet-based ideological and political education. It thus can be seen that the formation of connection relationship between subjects of education and objects of education must be based on giving play to the pivotal role of the method of internet-based ideological and political education in the process of internet-based ideological and political education.

\section{Preconditions of effective internet-based ideological and political education}

Famous educator and idealist in the Southern Song Dynasty Zhu Xi once said, "everything has its own solutions. As long as the solutions are found out, the thing can be done. If teachers give up proper teaching methods, they cannot teach well; of students give up proper learning methods, they cannot learn well”. What ancient people said is absolutely right. In educational process, the functions of "method" cannot be replaced. To achieve the objective of internet-based ideological and political education and accomplish educational tasks should be based on efficient activities of internet-based ideological and political education. The precondition of efficient activities of internet-based ideological and political education is to select correct educational methods. Thus, scientific and reasonable educational methods are required to improve teaching effects and influence of internet-based ideological and political education. If educational methods lack rationality in the process of internet-based ideological and political education, education will certainly get half the result with twice the effort and even make a futile effort. If wrong educational methods are selected, the actions and the objective are opposite, let alone ensure effectiveness of education. It thus can be seen that after educational objectives are set, it is still necessary to select scientific and reasonable so as to make sure the effectiveness of internet-based ideological and political education boost continuously.

\section{Structure of method system of internet-based ideological and political education}

The method of internet-based ideological and political education develops in practice. It reserves educational objectives and means of educational tasks. The law of internet-based ideological and political education, thought and behavior characteristic of people in the virtual society decide the method of internet-based ideological and political education. Besides, such method is a method, but a method system. Different methods in the method system can be applicable in different scopes so as to 
form the method system at different layers, including operational approach, specific method and principle method etc. Principle method is in the highest layer in the methods of internet-based ideological and political education, has guiding function for other methods and provides norms and requirements of other methods. Specific method refers to education decision, analysis of internet public opinion and internet information collection as well as practice methods of educational work such as comprehensive method, basic approach and special method. Specific method is of detailed application of principle method in internet-based ideological and political education. During internet-based ideological and political education, specific method plays the leading role in each link. Operational approach is of practical application of specific method in virtual practice and different forms of specific method in different conditions. Meanwhile, operational approach is summarized from specific method in virtual practice.

The method system of internet-based ideological and political education is jointly composed of the above three methods. Although the three methods are different in features, use conditions and application scope and have different layers, they are mutually related, can be mutually transformed, but cannot be replaced. High-layer methods need to be applied in virtual practice in the form of low-layer methods. Low-layer methods need to be guided by superior methods to ensure rationality and scientificity. For example, in internet-based ideological and political education, principle method guides use of specific method and operational approach. Meanwhile, principle method can be transformed to workers' working ability through specific method and operational approach so as to realize operability and give play to its values.

\section{New requirements of internet-based ideological and political education}

\section{Higher requirements for educational methods}

In internet-based ideological and political education, application of advanced information technology makes internet-based ideological and political education break through geographic limitation of traditional mode. Meanwhile, substantivity and authenticity under traditional education mode are lost. It can be seen that internet-based ideological and political education needs management and constraint by administrative means and more practical educational methods. Secondly, subjects of education are hidden in internet-based ideological and political education. It pays more attention to the form during imparting educational contents. Since the educational environment is complex and uncertainty of educational objects is strong, educational methods should be diversified and have high flexibility. Finally, internet-based ideological and political education is fast and rapid and the initiative of educational objects is strong, so educational methods should have strong effectiveness.

\section{Innovation of educational methods}

Traditional ideological and political education is difficulty to be applicable to internet-based ideological and political education, so the method of internet-based ideological and political education should be based on features of internet-based work and innovated in working thought, expression modem, operating system and educational means. In educational process, it is required to give play to the leading role of subjects of education and pay attention to establish relation of equality in the communication process. Information technology means as the carrier of education has the features of short life cycle and high technical content. The contents of internet-based ideological and political education need to improve readability and infection and be more vivid. The above various aspects require educational methods innovating in both contents and forms. Internet-based ideological and political education can play the guiding rime in solving new problems in practical life and boost foreseeability and effectiveness of internet-based ideological and political education only through innovation of educational methods.

\section{The promotion function of teaching methods on teaching effects is more obvious}

Firstly, planning and pertinence of education are enhanced. The method of internet-based ideological and political education requires guaranteeing effectiveness of education under trans-regional conditions. Thus, the requirements for designing education mode, arranging 
educational contents and setting educational objectives are higher. Planning and pertinence of education need to be enhanced. Secondly, adjustment is needed according to feedbacks in educational process. In the process of internet-based ideological and political education, through application of high and new information technology, subjects of education should timely know feedback information, adjust educational objectives and update educational contents according to needs of educational objects and feedback information so as to enrich educational contents and improve flexibility of educational work.

\section{Method innovation for internet-based ideological and political education - combination of internet means and traditional mode}

Current educational environment is influenced by internet and knowledge fusion. Value orientation, mental development, behavior pattern, moral idea and political attitude of college students are increasingly influenced by educational environment so that traditional education mode which help college students shape healthy character, establish correct values, standardize and guide behaviors of college students face new challenges.

\section{Combination of educational theme and information technology}

There is only one fundamental objective for internet-based ideological and political education, regardless of methods innovation or means innovation, i.e. carry forward scientific, healthy and positive ideology and culture in the ideology and culture, make college students improve their ability to distinguish wrong and harmful information, absorb correct and favorable information, make their spiritual state and ideology can still accept edification and infection of positive mainstream awareness, help them establish correct view of life, value and world view, cultivate their patriotism, make them stick to socialism and straggly or achieving great rejuvenation of Chinese nation. Therefore, during internet-based ideological and political education with information means, it is required to stick to main theme of ideological and political education, apply achievements of modern information technology, regard publicity and popularization of scientific theory as new contents of ideological and political education and allow main delusional theme scientized and modernized continuously in modern information environment.

\section{Strict management is required under enhanced information openness}

Current society is in the times of information explosion. Network information technology continuously develops. Information openness degree enhances continuously. In the virtual society, college students can contact great volume of information, including beneficial and harmful information. Pure prohibition or elimination of the above phenomena is not a long-acting method. Under the condition of numerous and complex network information, it is required to enhance network security management force and highlight the guiding role of ideological and political education. So, under the background of enhanced information openness, enhancement of management innovation means subjects of education should always keep open mentality in times development process, treat high and new technical achievements with positive attitude, broaden the horizon in information openness and improve self-ability. At the same time, it is necessary to strengthen information management, timely clear out information violating national policies and ethics and guard against erosion of bad information.

\section{Conclusions}

In current information times, internet-based ideological and political education is of great practical significance. Traditional ideological and political education is hard to be applicable to internet-based ideological and political education. So, we need to explore and innovate continuously in virtual practice and gradually perfect method system of internet-based ideological and political education. 


\section{Acknowledgments}

This paper is the topic of ideological and political education in colleges of Guangdong province in 2012: Study on interactive teaching system of ideological and political theory course in industry-dependent and enterprise-oriented vocational colleges (No.: 2012cy040); scientific research project of Guangdong AIB Polytechnic College in 2013: On ideological and political education under the background of butted campus and enterprise culture (No.: xyyb1304).

\section{References}

[1] Zeng Linghui: Study on internet-based ideological and political education - on principle method of internet-based ideological and political education, Journal of Guangxi Teachers College (philosophy and social science), 2011(7)

[2] Ma Lili: Analysis of construction of method system of internet-based ideological and political education, Journal of Hubei Correspondence University, 2013(3)

[3] Hao Yanjie, Sun Yu, Li Shuangyin: Research of problems and innovation of current internet-based ideological and political education, Education and Vocation, 2013(10)

[4] Chen Pi, Zhao Yi: Constructing of internet-based ideological and political education mechanism in new period, Management Engineer, 2013(10)

[5] Du Yanjiao: Study on development tendency of internet-based ideological and political education in colleges, Youth Literator, 2013(9)

[6] Mai Hanbin: Discussion of reform and innovation of ideological and political education of radio and television universities, Journal of Jilin TV \& Radio University, 2013(2) 